\title{
The Hypothalamic Ventromedial Nuclei Couple Activity in the Hypothalamo-Pituitary-Adrenal Axis to the Morning Fed or Fasted State
}

\author{
SuJean Choi, Cydney Horsley, Shirley Aguila, and Mary F. Dallman \\ Department of Physiology, University of California San Francisco, San Francisco, California 94143-0444
}

Function in the adrenocortical system is markedly altered by availability of food. Basal activity is lowest and stress responsivity highest in the morning when nocturnal rats eat $\sim 90 \%$ of their daily calories during the dark. After an overnight fast, basal corticotrophin and corticosteroid levels are elevated, and responsivity to stressors is decreased. Central neural sites that control these changes are unidentified. The hypothalamic ventromedial nuclei (VMN) appear to signal satiety; lesions result in increased food intake, obesity, and elevated basal insulin and corticosteroids. Thus, the VMN are good candidates for calorically mediated control of adrenocortical system function in satiated rats. We injected colchicine into the VMN to cause reversible inhibition of activity (Avrith and Mogenson, 1978) and tested the effects on basal and stimulated function in the adrenocortical system. Colchicine-injected rats that fed ad libi- tum exhibited increased basal but reduced corticotrophin and corticosterone responses to restraint in the morning compared with controls. By contrast, after an overnight fast, control rats had increased basal adrenocortical hormones and decreased stress responses that did not differ from colchicine-injected rats. Colchicine was visualized within cells in the VMN for up to $5 \mathrm{~d}$ using fluorescein/colchicine, and the treatment did not cause increased gliosis; moreover, the functional effects of the injections were reversed within $15 \mathrm{~d}$. We conclude that (1) the VMN serve to couple activity in the adrenocortical system to energy intake and (2) discrete colchicine injections provide a behaviorally and neuroendocrinologically useful period of inhibition without causing permanent functional damage.

Key words: adrenocorticotropin; corticosterone; obesity; insulin; reversible inhibition; colchicine
There is a tight association among food intake, caloric balance, and function in the hypothalamo-pituitary-adrenal (HPA) axis in all mammalian species (Dallman et al., 1995). Normally, at lights on, after rats have eaten to satiety, basal plasma corticotrophin (ACTH) and corticosterone (B) are at their trough, minimum levels. At this time, we have found that B values in fed, intact, unstressed rats do not differ significantly from those in adrenalectomized rats, suggesting that there is no hypothalamic drive to the HPA axis in the morning under basal conditions (Dallman et al., 1987). By contrast, toward the end of the light period as rats begin to eat, plasma ACTH and B levels rise and peak at lights out, when the major daily bouts of food intake begin (Dallman, 1984). Responsivity of the HPA axis to stress is highest in the morning, independent of B levels (Bradbury et al., 1991), and sensitivity to B feedback on stress responses is also highest in the morning (Akana et al., 1992b); both are diminished in the evening, before the first major meal of the day. Moreover, if rats are placed on a restricted feeding regimen, the normal diurnal rhythm in plasma ACTH and B adjusts to peak just before the time of feeding, and there is a marked reduction in ACTH and B in the first sample collected after food presentation (for review, see Dallman, 1984).

\footnotetext{
Received July 9, 1996; revised Sept. 13, 1996; accepted Oct. 1, 1996.

This work was supported in part by National Institute of Diabetes and Digestive and Kidney Diseases Grant DK-28172. S.A. was supported by National Institutes of Health Grant T35-MH18910-08. We thank Susan Akana, Seema Bhatnagar, Simon Hanson, and Alison Strack for their invaluable advice and assistance in both the experiments and the radioimmunoassays. We also thank John Sweetser for his technical advice on the optical density measurements and Kim Topp for sharing her experience with labeled colchicines.

Correspondence should be addressed to Dr. SuJean Choi, Department of Physiology, P.O. Box 0444, University of California-San Francisco, San Francisco, CA 94143-0444.

Copyright (C) 1996 Society for Neuroscience $0270-6474 / 96 / 168170-11 \$ 05.00 / 0$
}

In nocturnally feeding rats, a $14 \mathrm{hr}$ overnight fast provokes marked changes in regulation of the adrenocortical system. When rats are exposed to an overnight (14 hr) fast, basal ACTH and B increase and $\mathrm{ACTH}$ and $\mathrm{B}$ responses to stressors are diminished in the morning compared with ad libitum-fed rats; additionally, the sensitivity of restraint-induced ACTH to B feedback is diminished (Akana et al., 1994). When rats have had food removed but are given caloric gavages during the overnight "fasting" period, ACTH responses to restraint stress increase toward normal levels observed in rats fed ad libitum (Hanson et al., 1994). Therefore, both basal and stress-induced activity of the HPA axis appear to be controlled to a marked degree by satiation, or lack thereof, of the animal. However, the neural site that coordinates HPA axis with the state of satiety is unknown.

The ventromedial nuclei (VMN) appear to register satiety. Electrical stimulation of the VMN reduces food intake in hungry rats (Beltt and Keesey, 1975), and lesions of the VMN induce hyperphagia and obesity in all mammals that have been studied, including man (Bray and York, 1979). Lesions of the VMN cause increased food intake, hyperinsulinemia, and hyperactivity in the HPA axis under morning basal conditions (Dallman, 1984; Bray et al., 1990), including decreased sensitivity of ACTH to B feedback (Suemaru et al., 1995).

The VMN have both direct and indirect connections to parvocellular neurons in the paraventricular nuclei (PVN) (Ter Horst and Luiten, 1986; Canteras et al., 1994), where neurons synthesize corticotropin releasing factor (CRF) and vasopressin (AVP). When secreted from terminals in the median eminence, $\mathrm{CRF} /$ AVP increase synthesis and secretion of ACTH from the pituitary and, thence, B from the adrenals. Thus, the anatomical circuitry exists to support a regulatory role of the VMN on the HPA axis. 
As a result of VMN activity on food intake and regulation of HPA function and the association between HPA activity and food consumption, we examined a potential interaction between coupling of feeding and function in the HPA axis at the VMN using reversible inhibition with colchicine, as described by Avrith and Mogenson (1978). We tested effects of inhibition of VMN function on basal and stress-activated HPA indexes as well as circadian rhythms of food intake and body weight. As colchicine proved to be an effective inhibitor of VMN activity and function (in a dose-dependent manner), we then examined the anatomical localization of colchicine injections and consequential gliosis.

Parts of the work have been presented in abstract form at the 1996 International Congress of Endocrinology and the 1996 Society for Neuroscience meetings.

\section{MATERIALS AND METHODS}

In all experiments, male Sprague Dawley derived rats weighing 240-260 gm (Bantin \& Kingman, Fremont, CA) were used. Animals were housed singly in a $12 \mathrm{hr}$ light/dark cycle and maintained on free access to Purina rat chow (2008) unless specifically stated and water ad libitum. Two days before and for up to $15 \mathrm{~d}$ after VMN lesions, body weight and water and food consumption were usually measured daily during the light cycle. Food consumption was calculated by weighing food placed into food bins and subtracting the weight of noningested and spilled food at the end of the measurement period. The experiments and procedures were approved by the University of California San Francisco Committee on Animal Research.

Surgery and intracerebral injections. All rats were anesthetized with a rodent cocktail consisting of ketamine/xylazine/acepromazine (77/1.5/1.5 $\mathrm{mg} / \mathrm{ml} ; 1 \mathrm{ml} / \mathrm{kg}$, i.p.) and placed in a stereotaxic apparatus. Using a 28 gauge needle and microsyringe (Hamilton), artificial CSF (aCSF) $(0.1 \mu \mathrm{l})$ or colchicine (Sigma, St. Louis, MO) in aCSF $(0.1 \mu \mathrm{l})$ was injected into the VMN bilaterally using coordinates based on Paxinos and Watson (1986). The upper incisor bar was positioned at $-3.3 \mathrm{~mm}$ below horizontal zero. Coordinates were $2.6 \mathrm{~mm}$ posterior from bregma, $0.7 \mathrm{~mm}$ lateral to the midsagittal suture, and $9.2 \mathrm{~mm}$ below the surface of the skull. To reduce pressure damage and reflux, injections of either vehicle or colchicine into the VMN were made over $1 \mathrm{~min}$, followed by a $5 \mathrm{~min}$ period before the needle was removed. On completion of each experiment, animals were perfused and fixed with $0.15 \mathrm{M}$ phosphate buffer and ice-cold $4 \%$ formalin. Brains were post-fixed in $4 \%$ formalin for $24 \mathrm{hr}$ and then stored in a $30 \%$ sucrose in $0.1 \mathrm{M}$ PBS solution at $4^{\circ} \mathrm{C}$.

Experiments. Study 1 was performed to replicate and extend the observations made by Avrith and Mogenson (1978) on the behavioral effects of colchicine injected into the VMN. aCSF $(0.1 \mu \mathrm{l})$ or colchicine $(2.0 \mu \mathrm{g} / 0.1$ $\mu \mathrm{l})$ was injected bilaterally into the VMN (8 rats/group). Body weight and food consumption were measured every 9 (lights on) and 15 (lights off) hr beginning $2 \mathrm{~d}$ before surgery and for the first $13 \mathrm{~d}$ after injections. Thirty-six hours of food intake data are missing from this experiment because of experimenter illness.

Study 2. To assess whether colchicine produced a dose-dependent response on energy balance and to determine its effects on function in the HPA axis, aCSF $(0.1 \mu \mathrm{l})$ or colchicine $(0.5,1.0,2.0 \mu \mathrm{g} / 0.1 \mu \mathrm{l})$ was injected bilaterally into the VMN $(n=22)$. Two days before and up to $15 \mathrm{~d}$ after surgery, body weight and food consumption were measured every $24 \mathrm{hr}$ in the morning. Blood samples were taken in the morning (0900-1030 A.M.) from a small incision made in the lateral tail vein (Akana et al., 1992a). Blood $(\sim 0.2 \mathrm{ml})$ was collected in chilled tubes containing $0.3 \mathrm{M}$ disodium EDTA $(20 \mu \mathrm{l} /$ tube $)$. In both aCSF- and colchicine-treated animals, basal ACTH, B, and insulin levels were measured from blood collected from the tail. The collection was complete within $60 \mathrm{sec}$ of removing the rat from its cage and placing it in a Plexiglas restraining tube. A second blood sample was obtained after 30 min restraint (Akana et al., 1992a). After blood collection on day 15, the rats were anesthetized and perfused.

Two additional, independent experiments were performed in rats given $1 \mu \mathrm{g} / 0.1 \mu \mathrm{l}$ of colchicine or aCSF into the VMN. ACTH and B levels were measured in plasma samples collected at $30 \mathrm{~min}$ after the onset of restraint, in the morning, $5 \mathrm{~d}$ after surgery. In both experiments, functional inhibition by colchicine was verified by daily measurements of body weight and food intake; in one of these studies the rats were followed until food intake and body weight had normalized on day 10.
Study 3. To determine whether plasma insulin concentrations were elevated by inhibition of the VMN independently of increased food intake, injected rats were fasted before measurement of basal insulin and glucose in the morning. Rats were injected with aCSF $(0.1 \mu \mathrm{l} ; n=6)$ or colchicine $(1.0 \mu \mathrm{g} / 0.1 \mu \mathrm{l} ; n=6)$ in the VMN. To confirm that the VMN were functionally inhibited by colchicine, body weight and food consumption were measured every $24 \mathrm{hr}$ in the morning for $4-5 \mathrm{~d}$ after surgery. Food was removed before the onset of the dark period on day 4; all animals had ad libitum access to water. Within $2.5 \mathrm{hr}$ of lights on on day 5 , basal levels of insulin and glucose were measured in plasma from blood samples collected within $1 \mathrm{~min}$ of removing rats from their home cages. The fasted rats were then restrained for $30 \mathrm{~min}$ in Plexiglas tubes, and a final blood sample was collected for ACTH and B measurements.

Study 4. To determine whether the effects of inhibition of the VMN on responses of $\mathrm{ACTH}$ and $\mathrm{B}$ to stress were unique to restraint, we also measured the responses to insulin-induced hypoglycemia. Groups of rats were bilaterally injected in the VMN with aCSF $(0.1 \mu \mathrm{l})$ or colchicine $(1.0$ $\mu \mathrm{g} / 0.1 \mu \mathrm{l})$. To confirm that the VMN were functionally inhibited by colchicine, body weight and food consumption were measured for $4 \mathrm{~d}$. To ensure an adequate degree of insulin-induced hypoglycemia (Karteszi et al., 1982), both aCSF- and colchicine-treated rats were fasted overnight $4 \mathrm{~d}$ after surgery. On the following morning, insulin-induced hypoglycemia was produced in both aCSF- and colchicine-treated rats by injecting insulin (1 U/kg, i.p.; $n=5 /$ group). Separate aCSF- and colchicine-treated rats were injected intraperitoneally with saline to control for handling and injection ( $n=5$ /group). Before either insulin or saline injections, blood was collected from the tail to measure basal fasted ACTH and B levels. Sixty minutes after insulin or saline injections, all animals were decapitated and trunk blood collected. Trunk blood $(5 \mathrm{ml})$ was collected in chilled tubes containing $0.3 \mathrm{M}$ disodium EDTA (500 $\mu \mathrm{l} /$ tube).

Study 5. To determine the area of spread of colchicine in the hypothalamus, fluorescein/colchicine $(1.0 \mu \mathrm{g} / 0.1 \mu \mathrm{l}$; Molecular Probes, Eugene, OR) was injected bilaterally into the $\operatorname{VMN}(n=6)$. One hour $(n=1), 24$ hr $(n=4)$, and $5 \mathrm{~d}(n=1)$ after injections, rats were decapitated and their brains were fixed in a $10 \%$ formalin solution and then stored in a $30 \%$ sucrose, $0.1 \mathrm{~m}$ PBS solution. Brains were frozen and sectioned on a cryostat at $40 \mu \mathrm{m}$ thickness; every third slice was mounted using a nonfluorescing mounting medium containing an antifade agent, $\mathrm{N}$-propyl-gallate (4\%; Sigma). Adjacent sections were stained with cresyl violet.

Study 6. Comparisons of immunoreactive staining in aCSF-, colchicineand ibotenic acid-injected rats were made to assess any changes in glial proliferation using a glia-specific antiserum. Staining was measured in the brains from aCSF- and colchicine-injected rats from two of the experiments from study 2; one of $5 \mathrm{~d}$ and the other of $15 \mathrm{~d}$ duration. In an additional 14 male rats, bilateral ibotenic acid $(1 \% / 0.1 \mu \mathrm{l})$ or aCSF $(0.1$ $\mu \mathrm{l})$ injections into the VMN were made over a $5 \mathrm{~min}$ period using a 28 gauge microsyringe and a Sage Instruments electric syringe pump. After delivery of ibotenic acid, an additional 5 min delay was allowed before removal of the needle from the injection site. Five days after injection, rats were anesthetized and brains were perfused.

Immunocytochemistry. Sections of brain were cut on a freezing microtome at $40 \mu \mathrm{m}$, and every section through the VMN was collected and stored in cryoprotectant. Free-floating sections to be reacted with glial fibrillary acidic protein (GFAP) antibodies were incubated with $10 \%$ normal horse serum in $0.1 \mathrm{M}$ PBS solution for $20 \mathrm{~min}$ at $4^{\circ} \mathrm{C}$ and then were incubated with a monoclonal mouse anti-GFAP (1:1500; Boehringer Mannheim, Indianapolis, IN) in 0.1 M PBS cocktail containing $1 \%$ normal horse serum (Vector, Burlingame, CA), 0.3\% Triton X-100 (Sigma), and $0.25 \%$ BSA (Sigma) overnight at $4^{\circ} \mathrm{C}$. Sections were subsequently incubated with a biotinylated anti-mouse IgG (rat adsorbed) in horse (Vector), diluted 1:200 in the above PBS cocktail for $2 \mathrm{hr}$ at room temperature, washed, and then incubated with an avidin-biotin-peroxidase complex (Vector) for $2 \mathrm{hr}$ at $4^{\circ} \mathrm{C}$. 3,3-Di-aminobenzidine tetrahydrochloride (Sigma) with $0.003 \% \mathrm{H}_{2} \mathrm{O}_{2}$ was used as the chromagen.

Histological analysis. In rats injected with aCSF, ibotenic acid, and colchicine, immunoreactive staining for GFAP was measured quantitatively using optical density measurements [W. Rasband, National Institutes of Health (NIH) Image program]. Bilateral measurements were made in every section of the VMN in which there were visible signs of needle entry, such as red blood cells in the needle track or visible tears in the tissue. Optical density values in the VMN were recorded in a single field of view $(20 \times$ objective). In the same section, optical density measurements of background chromagen staining $(20 \times$ objective) in undisturbed cortical areas were subtracted from the VMN optical density 
measurements. Net optical density values represent the transmission of light through the VMN without background levels. This normalization controlled for different intensities of staining in different sets of tissues stained and allowed us to compare net optical density values among aCSF-, colchicine-, and ibotenic acid-injected animals. The majority of lesions were found throughout the anterior portion of the VMN.

In rats injected with fluorescein/colchicine, the criteria used to determine the borders of spread of the fluorescence were the presence of fluorescein/colchicine visible in cell bodies observed at a $63 \times$ objective. Using NIH Image program, we circumscribed the area containing fluorescent-positive cell bodies and calculated area in square millimeters.

In all animals with injections targeting the VMN, histology was performed to locate the needle tracks and injection site in cresyl violetstained sections.

Radioimmunoassays and glucose. Blood was centrifuged at $3000 \mathrm{rpm}$ at $4^{\circ} \mathrm{C}$ to separate plasma. Plasma samples were stored at $-20^{\circ} \mathrm{C}$ and used in radioimmunoassays for $\mathrm{ACTH}, \mathrm{B}$, and insulin. $\mathrm{ACTH}$ and $\mathrm{B}$ were assayed in duplicate when volume was sufficient.

Plasma ACTH was measured using a specific antiserum (kindly provided by Dr. W. C. Engeland, University of Minnesota) at a final dilution of 1:120,000 and $\left[^{125} \mathrm{I}\right] \mathrm{ACTH}$ as trace (Incstar, Stillwater, MN). There is $100 \%$ cross-reaction between the ACTH antiserum and ACTH1-39, ACTH1-18, and ACTH1-24 but not with ACTH1-16, $\beta$-endorphin, $\alpha$ and $\beta$-melanocortin stimulating hormone and $\alpha$ - and $\beta$-lipotropin $(<1 \%)$. Plasma was incubated for $48 \mathrm{hr}$ at $4^{\circ} \mathrm{C}$ with antiserum and labeled $\mathrm{ACTH}$, then incubated with precipitation serum (Peninsula Labs) for 2 hr. After centrifugation at $2000 \times g(3000 \mathrm{rpm})$ for $45 \mathrm{~min}$ at $4^{\circ} \mathrm{C}$, the pellet containing bound ACTH was counted with a gamma spectrometer. The minimum level of detection of the assay was $10 \mathrm{pg} / \mathrm{ml}$.

Plasma B was measured using a highly specific corticosterone antiserum (B3-163, Endocrine Sciences, CA) that cross-reacts slightly with desoxycorticosterone $(\sim 4 \%)$ and cortisol $(<1 \%)$. Corticosteroid-binding globulins were heat-denatured $\left(3 \mathrm{~min}\right.$ at $\left.>60^{\circ} \mathrm{C}\right)$. The plasma was incubated with $\mathrm{B}$ antiserum and $\left[{ }^{125} \mathrm{I}\right] \mathrm{B}$ (Incstar) overnight at $4^{\circ} \mathrm{C}$. Bound $\mathrm{B}$ was separated from free B by charcoal precipitation, centrifuged for 20 min at $2000 \times g(3000 \mathrm{rpm})$ at $4^{\circ} \mathrm{C}$. The minimum level of detection of the assay was $0.1 \mu \mathrm{g} / \mathrm{dl}$. Insulin was measured with an RIA kit and rat insulin standards (Linco, St. Charles, MO). The limit of detection was $0.1 \mathrm{ng}$ insulin/ml. Plasma glucose was measured enzymatically (Glucose analyzer II, Beckman Instruments, Fullerton, CA).

Statistical analysis. Data were analyzed using ANOVA corrected for repeated measures (when required). When main effects were significant, Newman-Keuls analysis was used to test significance of post hoc effects. When only two groups were compared, Student's unpaired $t$ test was used. All statistical analyses were conducted using commercial statistical software packages (JMP, SAS Institute; CLR ANOVA, Clear Lake Research). Statistical significance was established at $p<0.05$.

\section{RESULTS}

\section{Functional effects of colchicine injections and their reversibility with time}

Figure 1 shows the consequences of $2 \mu \mathrm{g}$ of colchicine or aCSF injected into the VMN bilaterally on day 0 on body weight and food intake measured at 9 and $15 \mathrm{hr}$ intervals for the $2 \mathrm{~d}$ before and for most of the $12 \mathrm{~d}$ after the injections. Before the injections, body weight increased during the dark and fell slightly during the daytime in both groups (Fig. 1, top), providing clear confirmation of the fact that the majority of feeding occurred during the dark $(\sim 90 \%)$, with little daytime $(\sim 10 \%)$ feeding in all rats (Fig. 1, bottom). Anesthesia, surgery, and injection into the brain on day 0 disrupted body weight gain and feeding in both groups during the first day or so. However, by day 3 after injections, the presurgical patterns of body weight gain and food intake were reestablished in the rats injected with aCSF (Fig. 1, open squares). By contrast, colchicine injections produced an immediate effect on body weight gain and food intake that was sustained for the first $8 \mathrm{~d}$ after injection (Fig. 1, filled circles).

From 1 until $8 \mathrm{~d}$ after injection, body weight was significantly greater in colchicine-injected rats with significant effects of time and time $\times$ treatment interaction. Moreover, both body weight

\section{Body Weight (g)}

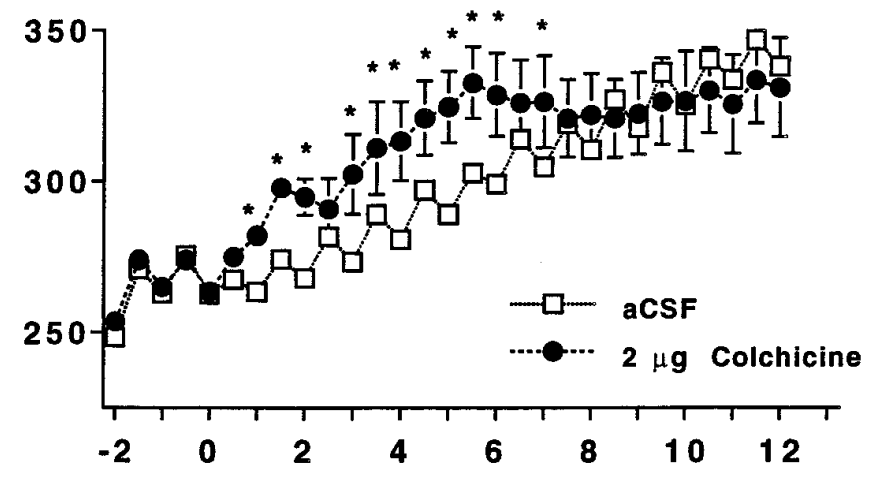

\section{Food Intake (g)}

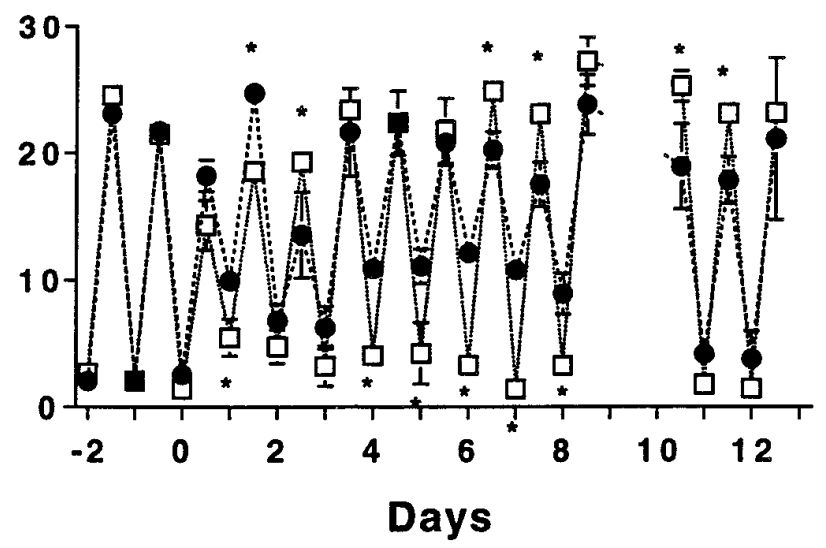

Figure 1. Body weight and food intake measured in study 1 at 9 and 15 hr intervals before and after aCSF or colchicine was injected bilaterally into the VMN at day 0 ( $n=8$ /group). Body weight for days $1-8$ showed significant main effects of drug $\left(F_{(1,14)}=8.73, p<0.009\right)$, time $\left(F_{(14,196)}=\right.$ $64.49, p<0.0001)$, and drug $\times$ time interaction $\left(F_{(1,196)}=4.92, p<\right.$ $0.0001)$. Food intake over days $1-8$ also showed significant main effects of $\operatorname{drug}\left(F_{(1,15)}=5.32, p<0.04\right.$, time $)\left(F_{(15,180)}=69.07, p<0.00010\right)$, and drug $\times$ time interaction $\left(F_{(1,180)}=6.67, p<0.0001\right)$. Means (symbols) are accompanied by \pm SEM (T-bars), and post hoc significance between groups is indicated by asterisks.

and food intake measures show that rats injected into the VMN with colchicine significantly increased their daytime food intake between days 0 and $8(\sim 32 \%$ of the total) compared with a minor increase in the vehicle-injected controls $(\sim 15 \%$ of the total). Body weight in the colchicine-injected rats returned to control values between day 7 and day 9 and remained there, accompanied by a reduction in food intake primarily during the dark, which was significant on days $6,7,10$, and 11 . On day 12 , food intake had completely regained its normal pattern, and the colchicine-treated group did not differ at either time of day from controls.

Colchicine inhibition of the VMN, in a dose-dependent manner, increased body weight over postsurgical days 1-8 and increased food intake over postsurgical days 1-6 compared with aCSF-treated rats (Fig. 2). Colchicine or aCSF injections were made on day 0 . ANOVA of body weight across days 1-6 indicated a significant difference with respect to time and dose and a dose $\times$ time interaction. Significant differences in food intake were observed with respect to time and dose and a dose $\times$ time interaction over days 1-6. Inspection of the results in Figure 2 suggests 


\section{Body Weight (g)}

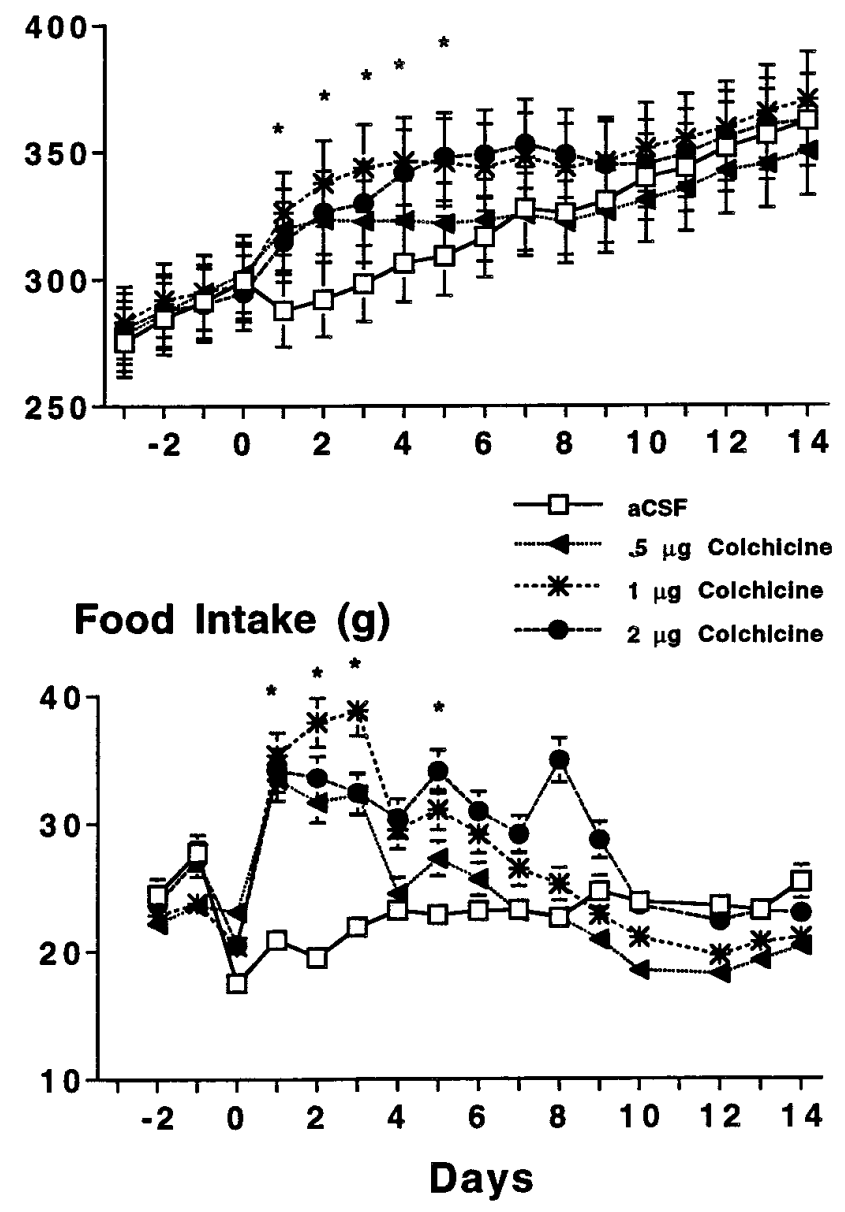

Figure 2. Dose-dependent changes in body weight and food intake between control rats $(a C S F)$ and rats injected bilaterally with one of three doses of colchicine (day 0$)$ into the VMN in study 2 ( $n=4-6 /$ group for aCSF, low, medium, and high doses of colchicine, respectively). Body weight over days $1-6$ showed significant main effects of drug $\left(F_{(3,5)}=3.26\right.$, $p<0.05)$, time $\left(F_{(5,85)}=39.15, p<0.0001\right)$, and drug $\times$ time interaction $\left(F_{(15,85)}=5.65, p<0.0001\right)$. Food intake over days $1-6$ also showed significant main effects of drug $\left(F_{(3,5)}=5.32, p<0.01\right)$, time $\left(F_{(5,85)}=\right.$ $16.28, p<0.0001)$, and drug $\times$ time interaction $\left(F_{(15,85)}=1.92, p<0.03\right)$. Asterisks are as in Figure 1.

that the effects of the lowest dose persisted for a shorter time than those of the higher two doses. There were no significant main differences between vehicle- and colchicine-treated rats over days 7-15 in either body weight gain or food intake.

During the period of colchicine inhibition of the VMN (days 2 and 5), both ACTH and B levels were elevated above those measured in vehicle-treated animals. However, by day 15, ACTH and $\mathrm{B}$ had returned to values similar to those for controls (Fig. 3). ANOVA of basal A.M. ACTH showed overall significant main effects of drug and time. In rats injected with colchicine, basal A.M. ACTH levels were significantly different across time $(0.5 \mu \mathrm{g}$, $p<0.02 ; 1.0 \mu \mathrm{g}, p<0.01 ; 2.0 \mu \mathrm{g}, p<0.002)$, whereas there were no significant changes across time in aCSF-injected animals (Fig. 3 , top ). On day 2, there was a significant difference within the various treatments $(p<0.002)$. Post hoc analysis revealed a significant difference in ACTH between aCSF- and colchicine- (2 $\mu \mathrm{g})$ treated rats $(p<0.01)$.
ANOVA of basal A.M. B levels (Fig. 3, middle) indicated overall significant main effects of drug and time. Similar to those for ACTH, B levels were significantly different across time $(0.5 \mu \mathrm{g}, p<0.01 ; 1.0$ $\mu \mathrm{g}, p<0.03 ; 2.0 \mu \mathrm{g}, p<0.05)$ in colchicine- but not aCSF-injected rats. On day 5 , there were significant differences between treatments. Post hoc analysis showed significantly different B levels between aCSF- and colchicine $(0.5 \mu \mathrm{g})$-injected rats.

Insulin was also measured (Fig. 3, bottom); however, an insufficient volume of plasma prevented complete analysis in all groups and more than one measurement in some groups. Insulin values that were obtained are shown in Figure 3. As with the adrenocortical hormones, it appears that insulin in colchicine-treated animals was increased on days 2 and 5, whereas by day 15, insulin had decreased to control levels.

Four days after colchicine $(1 \mu \mathrm{g})$ or aCSF injections into the $\mathrm{VMN}$, animals were fasted overnight. Insulin and glucose were measured in plasma collected the following morning (Fig. 4). Insulin levels were significantly elevated in colchicine-treated, fasted rats $5 \mathrm{~d}$ after injections compared with controls $(p<0.002)$ (Fig. 4, top). Glucose was not significantly different between aCSF- and colchicine-injected rats after the overnight fast (Fig. 4, bottom).

The animals from the colchicine dose-response study (Figs. 2, 3) were also exposed to restraint during and after the period of colchicine inhibition (Fig. 5). ACTH and B were significantly decreased $30 \mathrm{~min}$ after the onset of restraint during the period of colchicine-induced inhibition of the VMN (2 and $5 \mathrm{~d}$ ). ACTH was significantly decreased in colchicine-treated rats compared with controls on day 2 , and on day 5 , there were significant decreases in both $\mathrm{ACTH}$ and $\mathrm{B}(p<0.05)$. There were no significant differences in ACTH and B levels among groups on day 15 .

Versions of this experiment were repeated twice; once rats were tested on days 2, 5 and 10 after aCSF and colchicine injections into the VMN, and the other time, similarly prepared rats were tested only on day 5 after VMN injections. The results of both experiments showed significantly elevated basal B levels (data not shown) and marked hyporesponsiveness of ACTH to restraint in colchicine-injected rats tested at $5 \mathrm{~d}$ (Fig. 6, left and middle). Comparison of ACTH 30 min after restraint again showed aCSFinjected rats to have much higher ACTH than colchicine-treated rats (both experiments, $p<0.01$ ). The ACTH responses to $30 \mathrm{~min}$ restraint in the rats fasted overnight tended to be decreased in the colchicine-injected rats compared with the aCSF controls. However, unlike the remarkable inhibition observed in ad libitum-fed rats injected with colchicine in the VMN, the results in fasted rats were not significantly different (both, $p>0.05$; Fig. 6, right).

HPA responses to insulin-induced hypoglycemia were tested next in rats that had been injected with $1 \mu \mathrm{g}$ of colchicine or aCSF $5 \mathrm{~d}$ earlier. Because these animals were fasted overnight to reduce a hepatic source of glucose, preinsulin ACTH and B levels were slightly elevated above basal in the rats injected with aCSF but not with colchicine (Fig. 7, left). Plasma B $(p<0.025)$ but not ACTH $(p=0.1095)$ was significantly lower in the colchicine-treated group than in controls. Sixty minutes after injection of insulin, colchicine-treated rats had decreased plasma ACTH but not B responses compared with aCSF rats (Fig. 7, right). In one colchicine-treated rat, the injection of insulin did not lower plasma glucose at $60 \mathrm{~min}(90.8 \mathrm{mg} / \mathrm{dl})$; all results from that rat were eliminated from analysis of the response. Plasma glucose concentrations were markedly reduced in the remaining rats in both groups, indicating that the hypoglycemic stimulus was adequate $(28 \pm 4$, vs $34 \pm 1 \mathrm{mg} / \mathrm{dl}$, colchicine vs aCSF). 


\section{ACTH $\mathrm{pg} / \mathrm{ml}$}
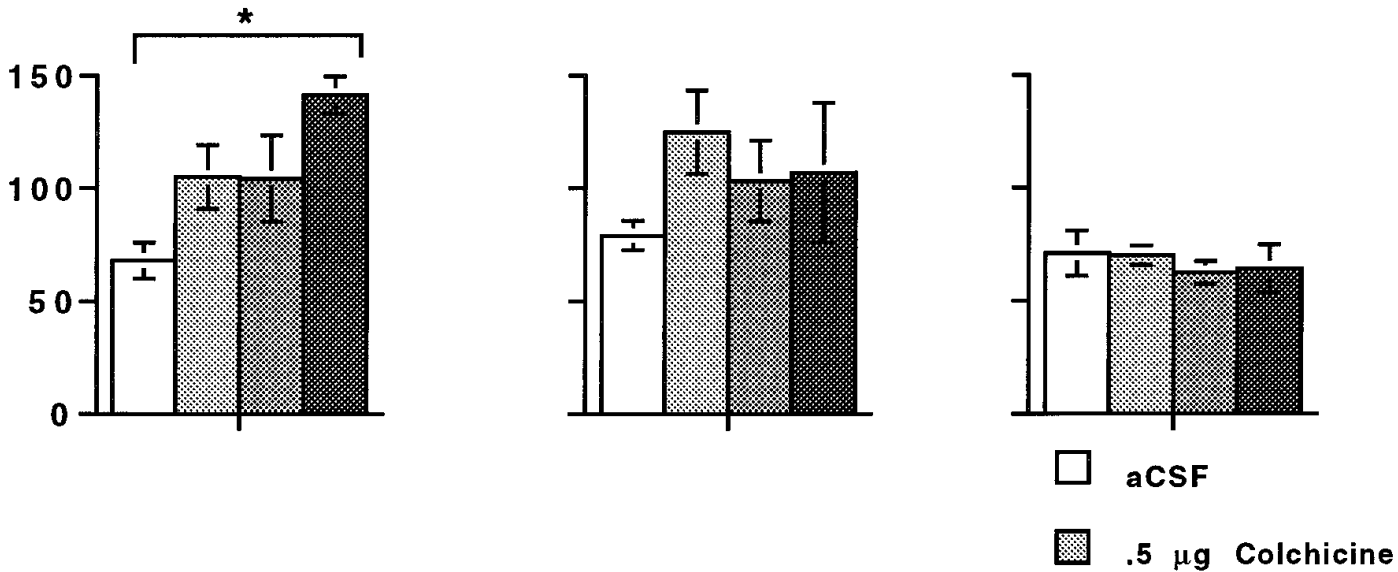

\section{Corticosterone $\mu \mathrm{g} / \mathrm{dl}$}
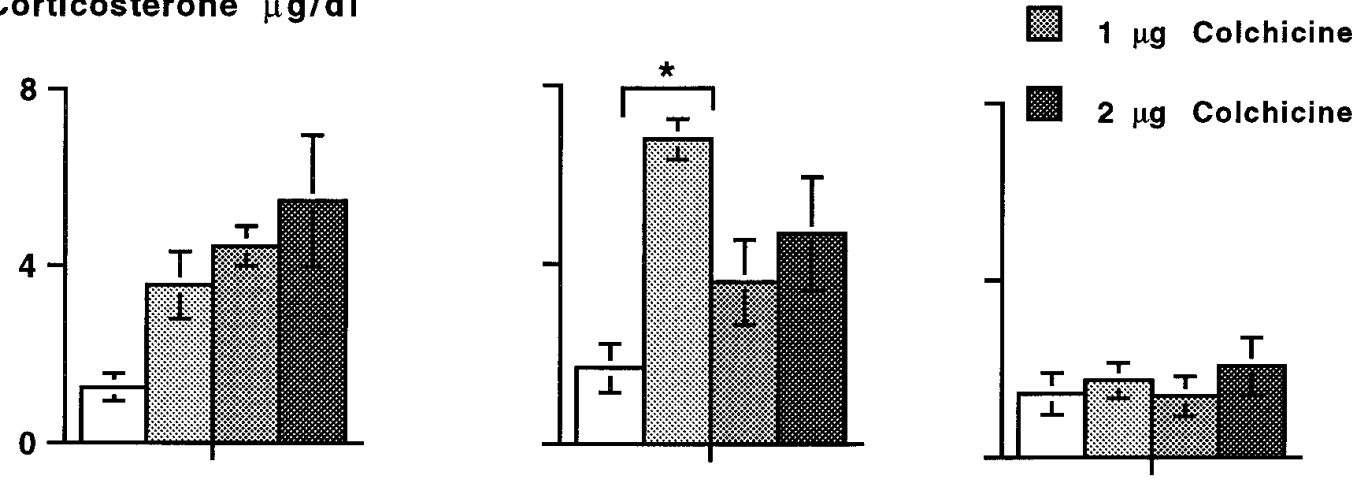

Insulin $\mu \mathrm{U} / \mathrm{m} \mathrm{I}$

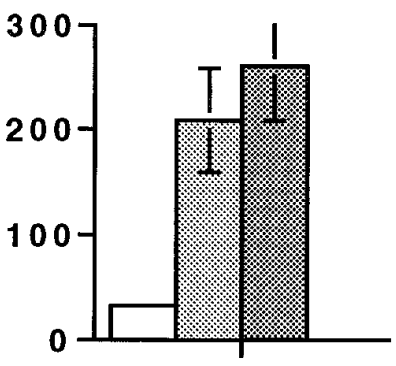

Day 2

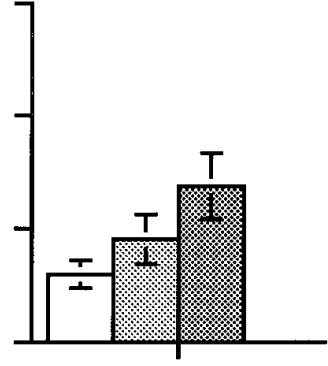

Day 5

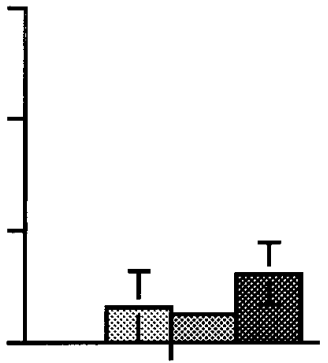

Day 15

Figure 3. Basal hormone levels collected across time from control rats $(a C S F)$ or rats injected bilaterally with one of three doses of colchicine into the VMN in study 2. Basal plasma ACTH (top) and corticosterone (middle) concentrations, collected from rats fed ad libitum in the morning, were different by ANOVA in colchicine- compared with aCSF-injected groups on days 2 and 5; by day 15, values did not differ among groups. ACTH: drug $\left(F_{(3,2)}=\right.$ $3.28, p<0.05)$ and time $\left(F_{(2,34)}=11.24, p<0.0002\right)$; corticosterone: $\operatorname{drug}\left(F_{(3,2)}=3.62, p<0.03\right)$ and time $\left(F_{(2,34)}=7.95, p<0.0015\right)$. Asterisks are as in Figure 1. Plasma insulin levels (bottom) represent results from between 2 and 5 rats/time/group and were not subjected to analysis.

\section{Anatomical localization and persistence of colchicine and gliosis induced by injections}

To estimate the site and spread of injectate, fluorescein/colchicine was injected into the VMN bilaterally (Fig. 8). At $5 \mathrm{~d}$ after injection into the VMN, the spread of fluorescein/colchicine was $0.15 \pm 0.01$ $\mathrm{mm}^{2}$. In addition, there was clear evidence for intracellular colchicine (Fig. 8, middle). Adjacent sections were stained with cresyl violet and used to verify that fluorescein/colchicine injections were generally placed in the anterior VMN. No evidence of fluorescence was detected in the arcuate nuclei, the PVN, or the lateral hypothalamic nuclei. Colchicine injected into the wrong site (Fig. 9, Missed) did not produce the same effect on either body weight or the ACTH re- sponse to $30 \mathrm{~min}$ of restraint compared with successful colchicine injection into the VMN.

To ascertain the degree of neuronal damage resulting from colchicine injections, we compared immunoreactive staining for GFAP among rats injected in the VMN with aCSF, colchicine, or ibotenic acid (which produces an excitotoxic lesion). GFAP is an intracellular protein that is specifically associated with astrocytes (Raff et al., 1979). Frequently, glia proliferate in response to cellular injury (Takamiya et al., 1988) and, thus, gliosis has been used by others to delineate excitotoxin-induced lesions (Topp et al., 1989; Ritter and Calingasan, 1993). The optical density of GFAP staining in the VMN was similar in rats injected with aCSF 

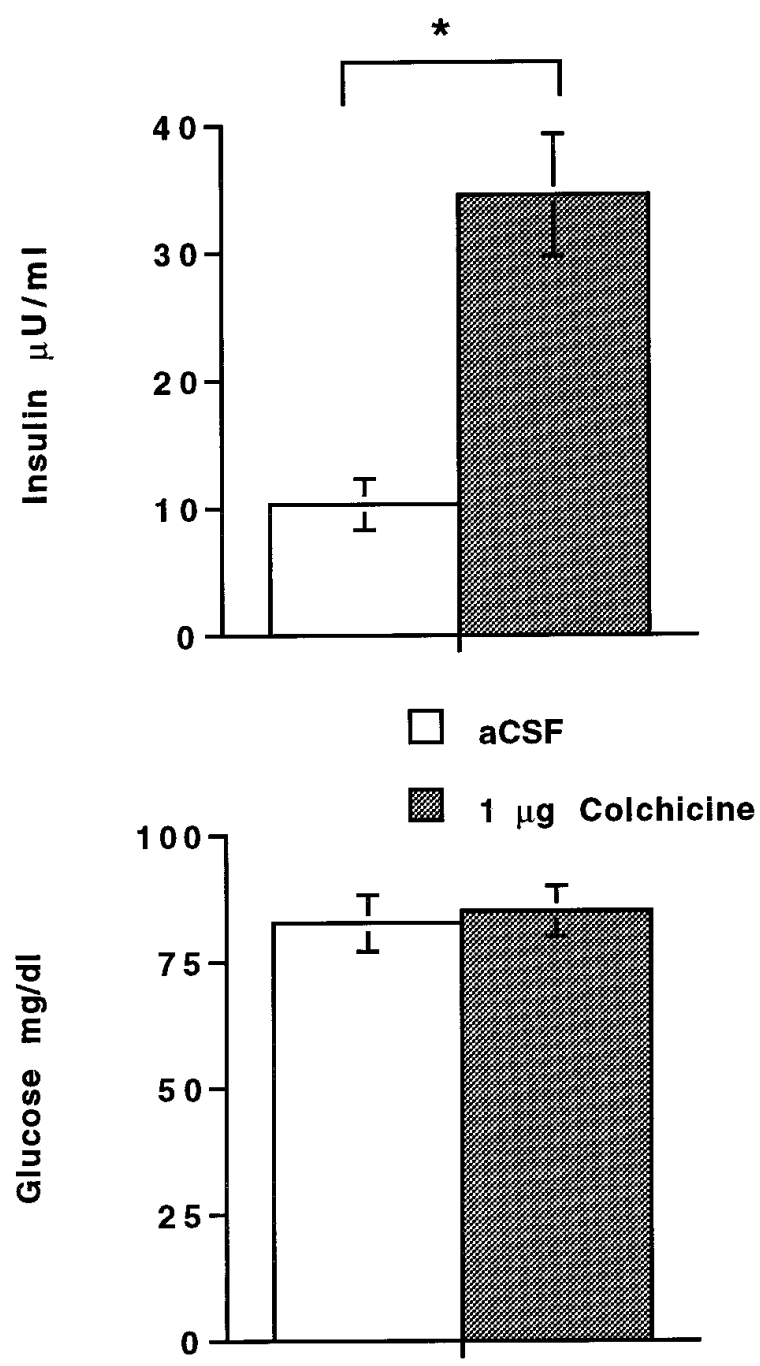

Figure 4. Plasma insulin (top) and glucose (bottom) concentrations in rats sampled in the morning after an overnight fast on day 5 after bilateral injections of vehicle (aCSF) or colchicine $(1 \mu \mathrm{g})$ into the VMN (study 3 ). Insulin levels were markedly stimulated in fasted rats with colchicine injections compared with aCSF $(p<0.002)$, although plasma glucose was similar and low in both groups.

or colchicine but was significantly greater $(p<0.001)$ in rats injected with the neurotoxin ibotenate (Table 1). Figure 10 shows that increased GFAP staining was localized to the damage caused by the cannula track used for injection in both aCSF- and colchicine-treated rats and that there was not increased gliosis at the injection site below the end of the track in colchicine-injected rats. The degree of GFAP staining below the cannula track was increased in rats injected with ibotenate.

\section{DISCUSSION}

The effects of transient inhibition of VMN activity by colchicine reveal that the normal activity of cell groups in the VMN exerts profound regulatory effects on HPA axis function. We propose that the VMN serve as one neural site from which satiation signals of ongoing energy balance control adrenocortical function. All measured functional effects of colchicine injections are fully reversible after $15 \mathrm{~d}$. Comparison of the effects of functional inhibition of VMN activity by colchicine with those that occur after permanent lesions shows them to be identical. Colchicine injected into the VMN exhibits highly limited distribution and induces no more gliosis than that which occurs as a consequence of introduction of the injection needle and aCSF. These characteristics strongly support the use of colchicine for inducing reversible inhibition of hypothalamic neural activity for periods of $\sim 1$ week.

\section{Functional effects of inhibition of the VMN}

In agreement with the results of Avrith and Mogenson (1978), bilateral injections of colchicine into the VMN produce dosedependent increases in both food intake and body weight gain, which are reversed with time. The period of colchicine inhibition appeared to last for $\sim 10 \mathrm{~d}$; by day 15 , food intake and body weight return to control levels. Normal rats are nocturnal and consume the majority of their food during the dark period; by contrast, colchicine-treated rats exhibited increased food consumption during the light period. The dampened diurnal rhythm in food intake and body weight gain in colchicine-treated rats is similar to that which occurs after permanent lesions (Bray and York, 1979; Dallman, 1984; Suemaru et al., 1995). For $\sim 6$ d after surgery, food intake begins to decline only during the night; daytime food intake remains elevated above normal for several more days. This suggests that other control sites are initially responsible for restoration of normal body weight after colchicine injection into the VMN.

Many chemical signals are potentially involved in regulation of food intake and satiety. Because white adipose depots increase during the period when food intake and body weight increase in colchicine-injected rats (data not shown), it is likely that concentrations of the circulating fat-derived satiety factor leptin (Zhang et al., 1994; Halaas et al., 1995) increase with time after colchicine. Leptin is known to act at receptors on neurons in the arcuate nuclei (Mercer et al., 1996) that synthesize and secrete NPY, a potent orexigenic factor, into the PVN (Clark et al., 1984). Insulin, another satiety factor that inhibits NPY (Schwartz et al., 1992), is also elevated in colchicine-injected animals. The VMN are more electrically active during light, when they are believed to signal satiety (Bray and York, 1979), than during dark (Koizumi and Nishino, 1976). It may be that the elevated leptin and insulin signals resulting from inhibition of the VMN and increased fat stores act consistently to inhibit NPY secretion throughout the 24 hr day. However, inhibition of VMN activity during light may be a more powerful orexigenic signal than the anorexigenic signals produced by leptin and insulin. These satiety cues would then be overridden during the day by inhibition of the VMN, but they would be perceived normally during the night, when the VMN are inactive. Consequently, although colchicine inhibits the VMN in the light period, the increased obesity that is signaled through leptin and insulin may result in decreased night-time food intake.

Colchicine-induced inhibition of VMN function resulted in elevated basal A.M. ACTH and B secretion and hyperinsulinemia for at least $5 \mathrm{~d}$. These responses are identical to those that have been observed in rats after permanent electrolytic or ibotenic acid lesions in VMN (Krieger, 1980; Inouye, 1982; Shimizu et al., 1987; Zaia et al., 1987; Suemaru et al., 1995) and markedly resemble the effects of an overnight fast (see introductory remarks). After permanent lesions of the $\mathrm{VMN}$, trough $\mathrm{B}$ is consistently elevated above control for as long as measurements are made and does not entirely recover as it did by day 15 after colchicine injections (Honma et al., 1987). Elevated plasma insulin concentrations in fasted as well as fed rats and persistently elevated basal corticosteroid levels after colchicine injection are hallmarks of the VMN syndrome and metabolically induced obesity (Bray et al., 1990). 


\section{ACTH $\mathrm{pg} / \mathrm{ml}$}

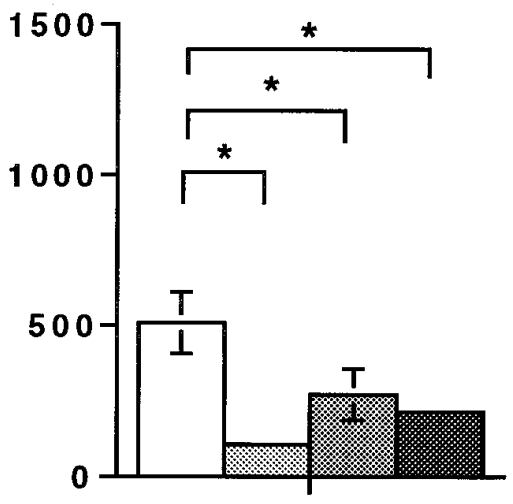

\section{Corticosterone $\mu \mathrm{g} / \mathrm{dl}$}

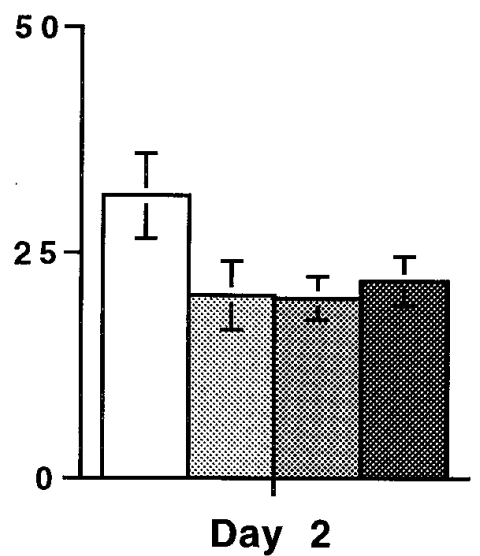

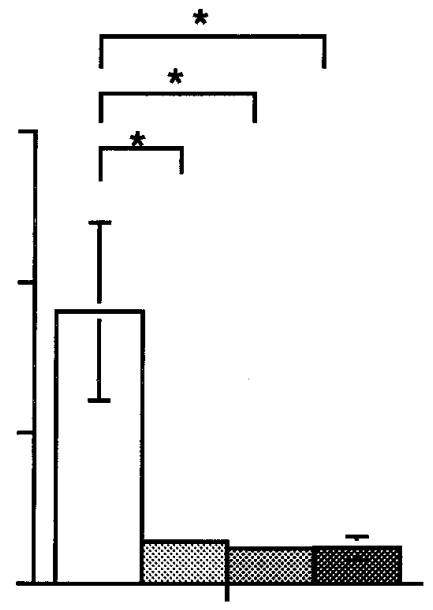

$.5 \mu \mathrm{g}$ Colchicine

$1 \mu \mathrm{g}$ Colchicine
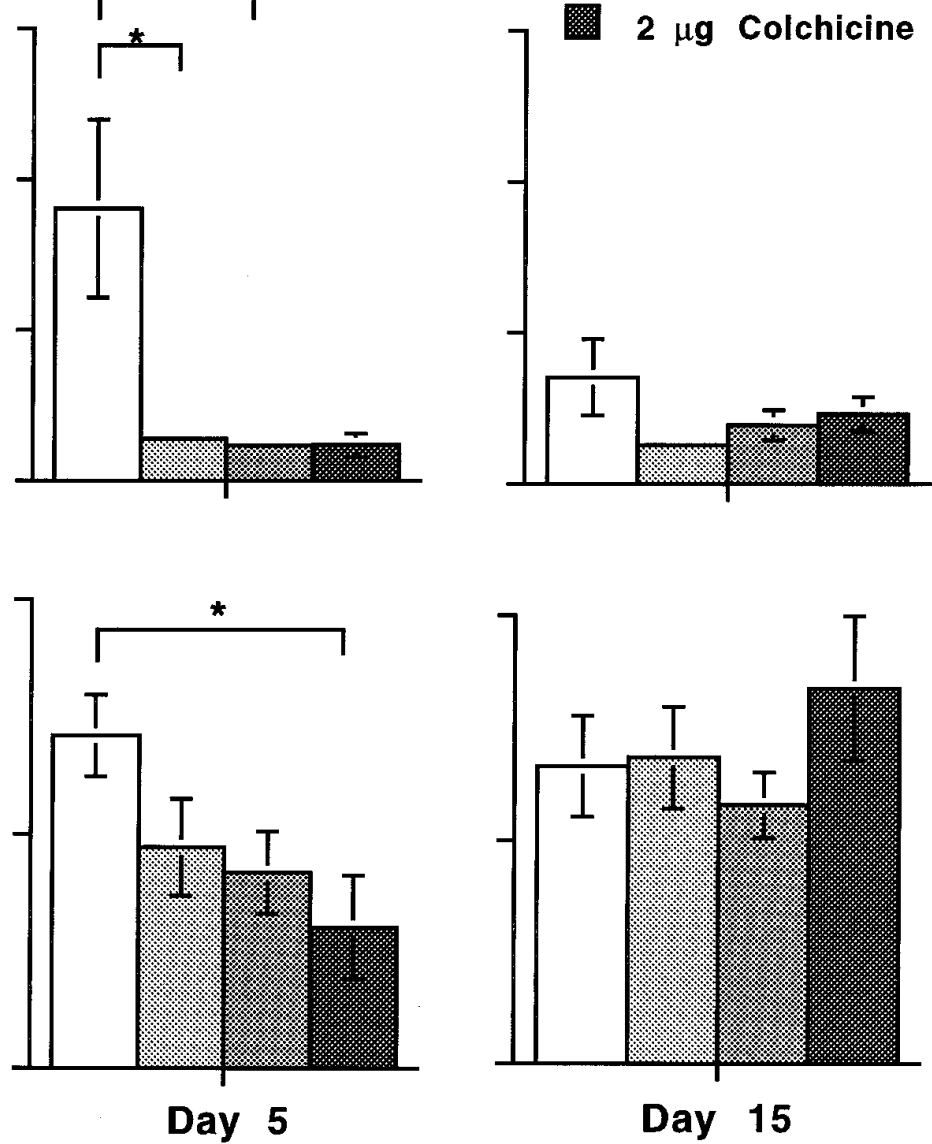

Figure 5. Plasma ACTH (top) and corticosterone (bottom) measured after $30 \mathrm{~min}$ of restraint in rats from study 2 . Both hormonal responses were diminished in colchicine-treated rats on days 2 and 5 (ANOVA) but did not differ from aCSF-treated controls on day 15 . ACTH: drug $\left(F_{(3,2)}=4.46, p<\right.$ 0.02). Corticosterone: time $\left(F_{(2,34)}=17.83, p<0.0001\right)$ and drug $\times$ time interaction $\left(F_{(6,34)}=3.92, p<0.004\right)$. Symbols are as in Figure 1 .

These studies have revealed a highly coherent, regulatory role of normal VMN function on the HPA axis in fed, satiated rats in the morning. Administration of colchicine or permanent lesions of the VMN elevate basal trough, but not peak B (Zaia et al., 1987; Egawa et al., 1991; Suemaru et al., 1995), similar to the effects of a 12-14 hr fast (Bradbury et al., 1991; Hanson et al., 1994). Moreover, inhibition of the VMN by colchicine reduces responsivity of the HPA axis in ad libitum-fed rats to stressors; after acute restraint, colchicine-injected rats had decreased ACTH and B compared with controls. Importantly, when both aCSF- and colchicine-treated rats were fasted overnight and then restrained, the significant difference in the ACTH and B responses between the two groups was abolished; both had elevated initial levels and diminished responsivity to restraint. Taken together with the feeding-associated regulation of HPA axis activity in normal rats (see introductory remarks), the VMN of the food-satiated rat normally appear to inhibit basal HPA function and potentiate HPA responses to restraint in the A.M.

Neurotoxin-induced VMN lesions attenuate counter-regulatory catecholaminergic and glucagon responses to insulin-induced hy- poglycemia (Borg et al., 1994); therefore, our finding of a diminished HPA response to this stimulus may be a specific consequence of the fact that colchicine injections inhibited activity in neurons in the VMN that are responsive to both glucose and insulin (Oomura and Kita, 1981; Ono et al., 1982). Others, measuring $\mathrm{B}$, but not $\mathrm{ACTH}$, do not find that VMN lesions alter responsivity to stressors (Bellinger et al., 1976; Suemaru et al., 1995); however, the corticosteroid response saturates in the lower range of stimulus-activated ACTH concentrations (Keller-Wood and Dallman, 1984) and is thus a relatively insensitive index of inhibition of HPA axis function.

\section{Anatomical distribution and gliosis after colchicine}

Examination of the spread of fluorescein/colchicine and the persistence of the fluorescent signal show that the injections had a highly discrete distribution within the VMN for at least $5 \mathrm{~d}$. Although the area of fluorescence-containing cells did not change over $5 \mathrm{~d}$ (data not shown), it is probable that fluorescein/ colchicine and colchicine spread beyond the cell bodies measured to nearby axons and dendrites. However, the focal area 


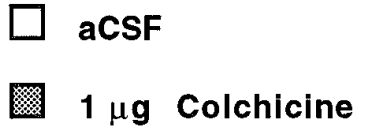

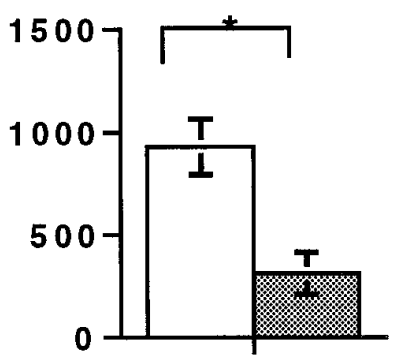

Fed ad lib

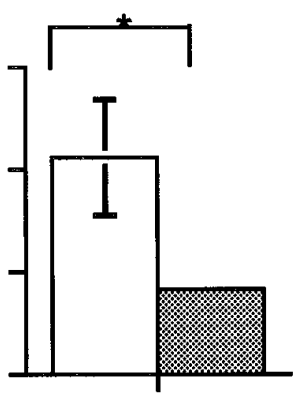

Fed ad lib

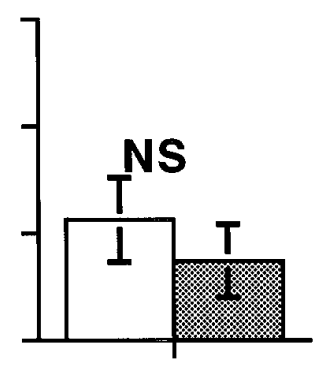

Fasted

Figure 6. Plasma ACTH 30 min after the onset of restraint in the morning in rats bilaterally injected into the VMN with either aCSF or colchicine 5 d earlier. In the left and middle, the groups fed ad libitum in study 2 are indicated, confirming the results in Figure 4; in the right, fasted rats in study 3 are indicated. Asterisks show differences $(p<0.01)$ between aCSF- and colchicine-injected groups.
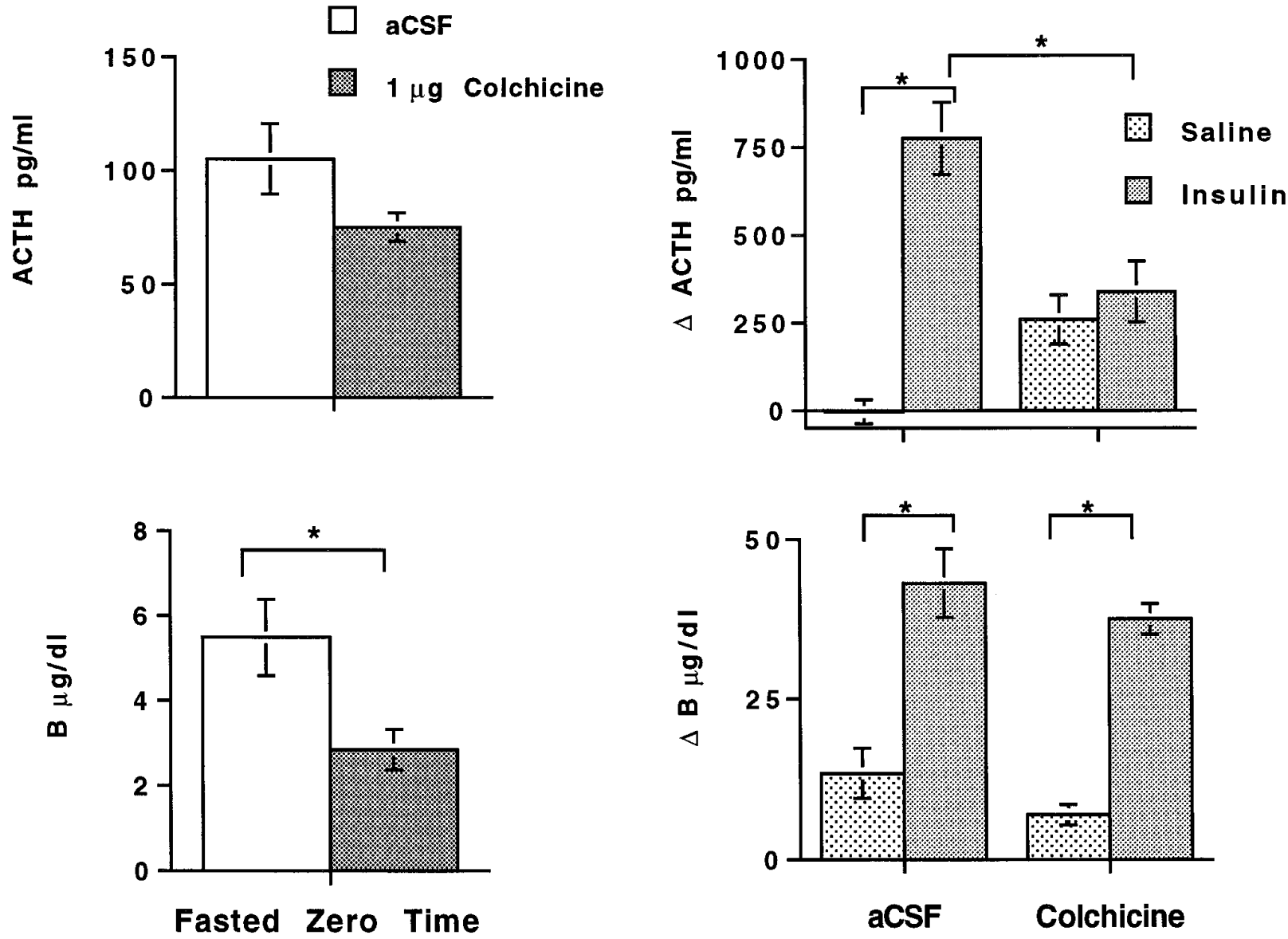

Figure 7. Initial ACTH and corticosterone (B) values (left, $n=10$ /group) and response at 60 min to insulin or saline given intraperitoneally (60-0 min values; $n=4-5$ /group). Rats had been injected into the VMN bilaterally $5 \mathrm{~d}$ previously with either aCSF or colchicine (1 $\mu \mathrm{g})$. Asterisks indicate significant differences $(p<0.05)$.

of injectate itself was consistently maintained over $5 \mathrm{~d}$. Because the labeled compound has a higher molecular weight than native colchicine, it is possible that the distribution of the native drug is more widespread. However, because cells are permeable to colchicine, which interferes with axonal transport by inhibiting the polymerization reaction between tubulin and microtubulin (Paulson and McClure, 1974; Wilson, 1975), we believe that it is likely that the fluorescently labeled compound 

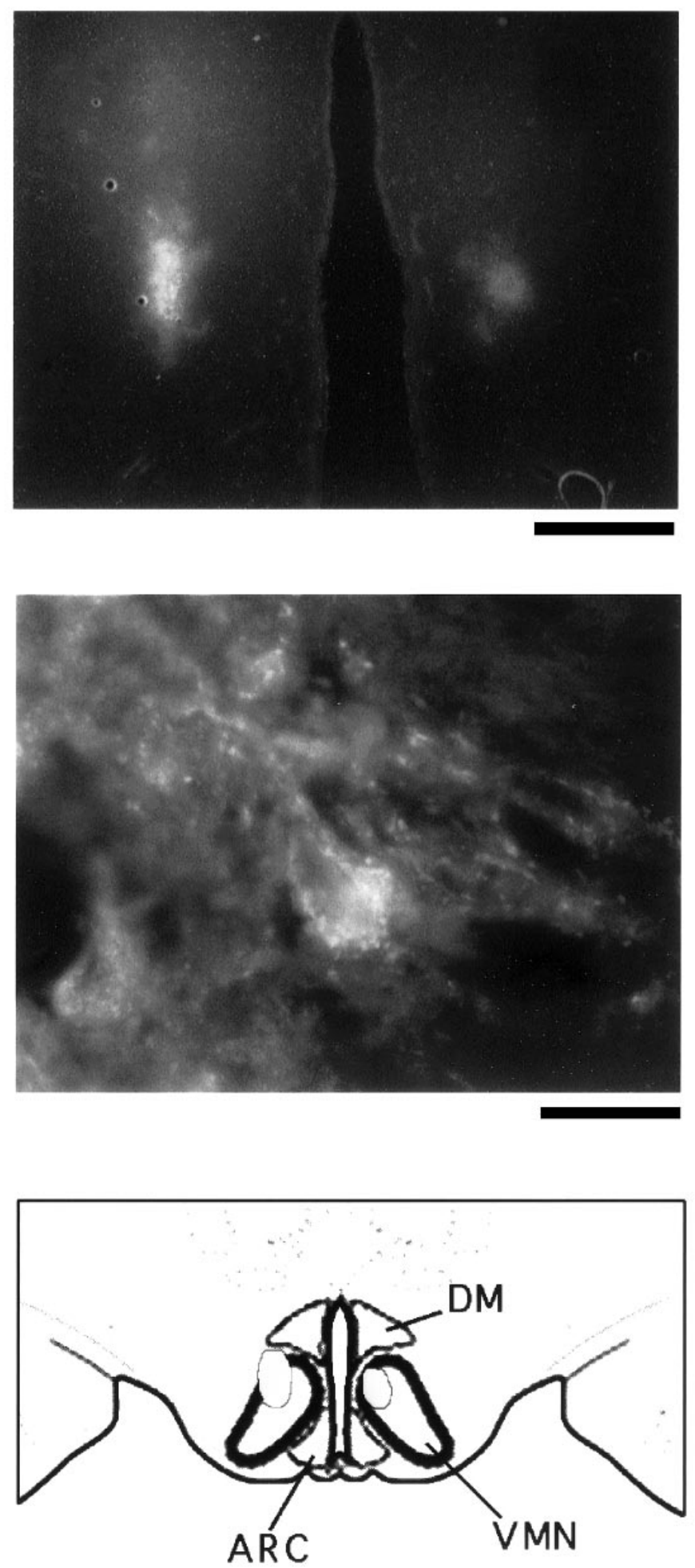

Figure 8. Localization of injected fluorescein/colchicine in the brain $5 \mathrm{~d}$ after bilateral injections. Scale bars represent $0.5 \mathrm{~mm}$ (left) for the top panel and $0.02 \mathrm{~mm}$ (middle) showing cellular localization of fluorescence. Bottom shows a schematic illustrating anatomical localization of injection (Swanson, 1992). DM, Dorsal medial n.; $A R C$, arcuate $\mathrm{n}$. Adjacent $40 \mu \mathrm{m}$ sections were stained with cresyl violet to ascertain placement of the drug. All bilateral injections were within or just above the VMN.
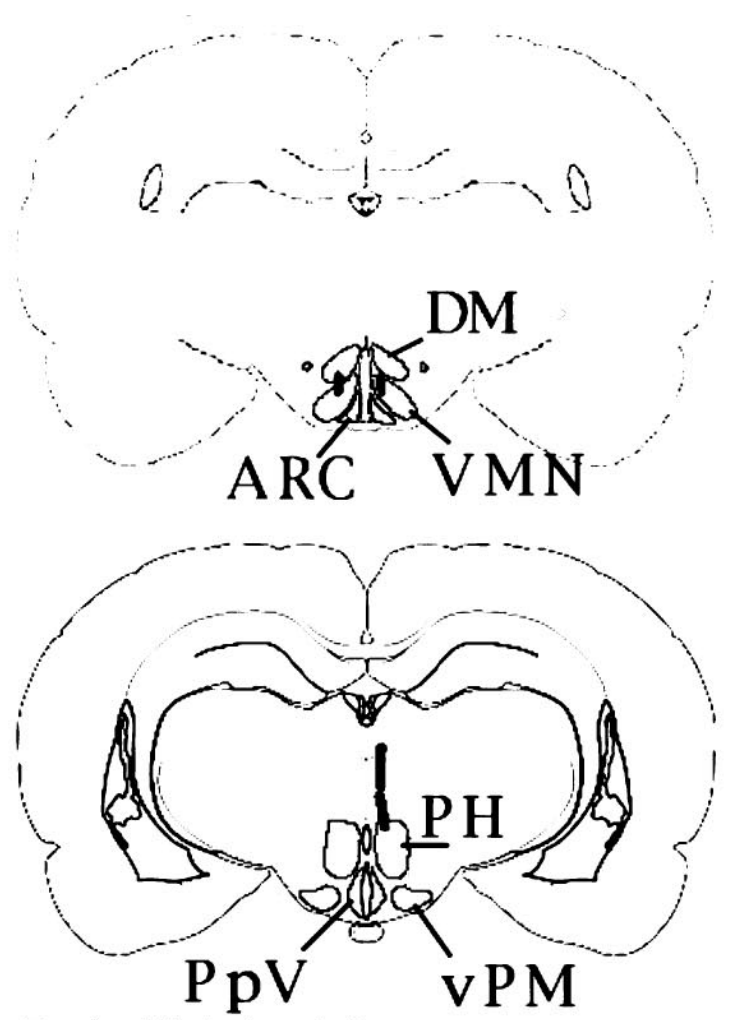

Body Weight (g)
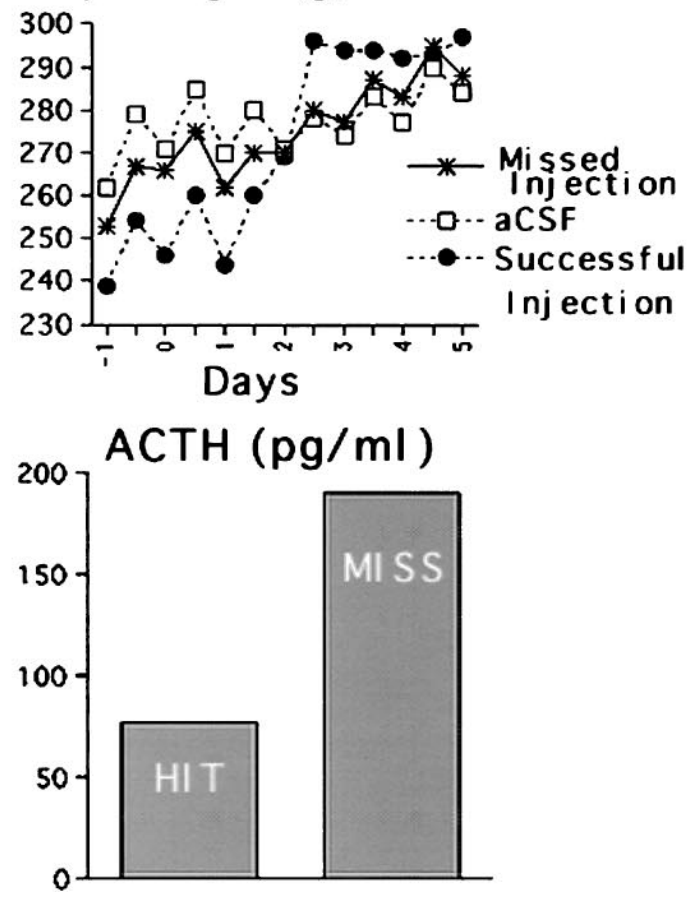

Figure 9. Mapped location of successful injection in the VMN (top panel). DM, Dorsal medial n.; ARC, arcuate n. Second panel shows that the needle tracks were unilateral and posterior to the VMN. $P p V$, Posterior periventricular n.; $v P M$, ventral premammillary n.; $P H$, posterior hypothalamic $\mathrm{n}$. Third panel shows body weight for the successful colchicine injection, the missed injection, and an animal injected with aCSF. The bar graph (bottom panel) shows ACTH responses after 30 min of restraint in both the VMN-injected and the colchicine misinjected-animal. 
Table 1. GFAP staining in the VMN quantified by optical density

\begin{tabular}{lll} 
aCSF & Colchicine & aCSF vs colchicine \\
\hline $0.050 \pm 0.012$ & $0.5 \mu \mathrm{g}: 0.067 \pm 0.014$ & NS \\
& $1.0 \mu \mathrm{g}: 0.085 \pm 0.023$ & NS \\
& $2.0 \mu \mathrm{g}: 0.067 \pm 0.028$ & NS \\
\hline
\end{tabular}

\begin{tabular}{lll} 
aCSF & Ibotenic acid & aCSF vs ibotenic acid \\
\hline $0.074 \pm 0.015$ & $1 \%: 0.148 \pm 0.011$ & $p<0.0002$
\end{tabular}

Gliosis caused by injections of aCSF, colchicine, and ibotenic acid into the VMN. The numbers represent the difference in optical density resulting from GFAP staining in an area at the injection site in the VMN versus a similar area in cortex from the same section (the area measured in each case was the entire field within a $20 \times$ objective). NS, Not significantly different.

provides an accurate estimate of the site at which colchicine exerts its effects.

Because cells that were labeled with fluorescein and the ends of the needle tracks were shown to lie predominantly within the dorsomedial, anterior portion of the VMN, it is clear that the effects observed were a consequence of the drug on VMN function. The results cannot be ascribed to spread of the injectate to other nearby hypothalamic cell groups such as the arcuate, lateral, or PVN. This is important, particularly in studies attempting to delineate the interactions among closely apposed hypothalamic cell groups, many of which are involved in overlapping functions on energy balance and hormone secretion.

Although colchicine may have blocked both activity of neurons in the VMN and fibers of passage, the functional results of the injections resemble those of both electrolytic and neurotoxininduced lesions (Sakaguchi et al., 1988; Tokunaga et al., 1989). Because injection of neurotoxins is believed to act primarily on neuronal cell bodies rather than on fibers of passage (Olney, 1971; Olney et al., 1971; Grossman et al., 1978), it is likely that the effects of the drug primarily reflect alteration of neuronal activity within the VMN rather than blocked activity of axons of passage that originate from neurons outside the VMN.

The lack of cytotoxicity induced by colchicine was mentioned regularly in previous studies but without objective quantification (Zolovick et al., 1977; Avrith et al., 1979). The relative GFAP staining in the VMN of rats treated with aCSF or colchicine showed no differences in the small amount of gliosis that occurs along the cannula track or in the VMN. By contrast, GFAP expression was increased in the VMN of rats injected with ibotenic acid, suggesting that the expected neuronal loss and resultant gliosis had occurred after neurotoxin injection. Although there may have been alterations in innervation patterns after release from the colchicine blockade, the fact that function returned by $15 \mathrm{~d}$ suggests that any neuronal plasticity that may have occurred as a consequence of the inhibition did not markedly disrupt reacquisition of normal function of the VMN.

We have validated anatomically the use of colchicine in induction of transient inhibition of the VMN and suggest that this technique will be useful for delineating function in other closely adjoining hypothalamic sites that are concerned with metabolic, behavioral, and endocrine regulation. The power of the technique is clear from the new functional relationships that it revealed between the VMN and control of the HPA axis, which resides in the neighboring CRF and AVP parvocellular neurons of the PVN.

\section{aCSF}

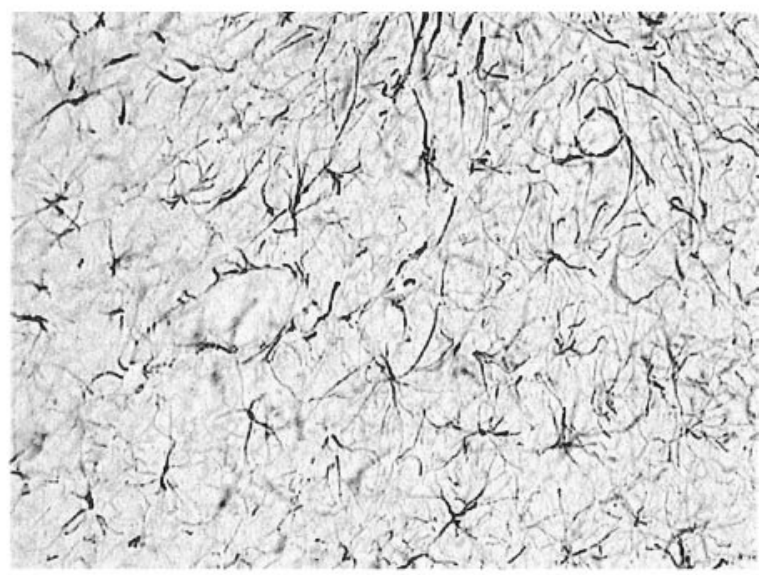

\section{Colchicine}

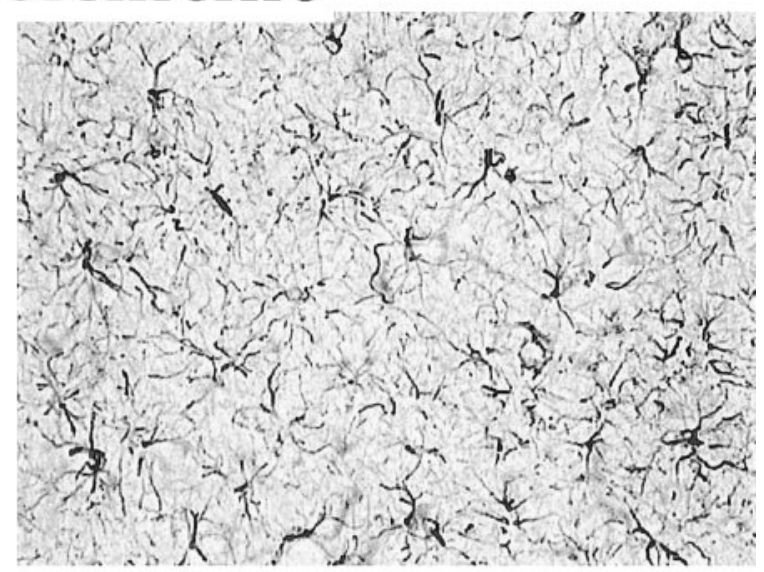

\section{Ibotenic Acid}

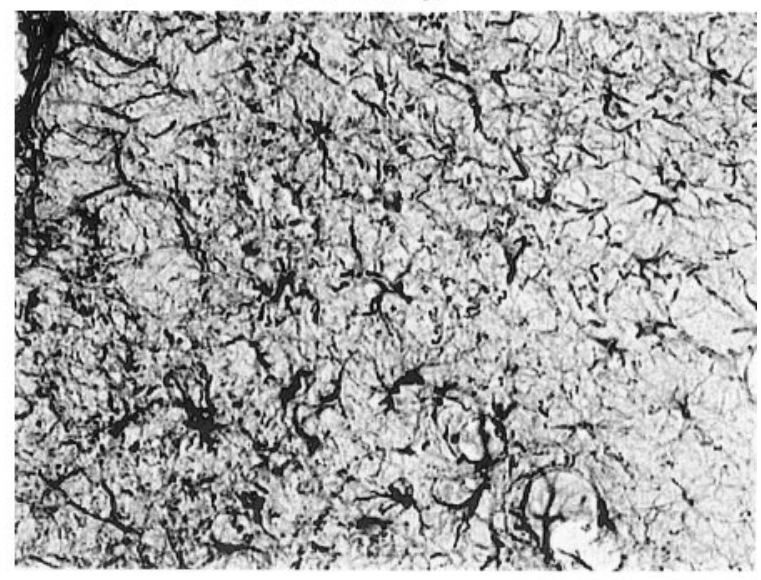

Figure 10. Brain sections immunostained with GFAP after bilateral injections into the VMN. Top, aCSF injections; middle, colchicine injections; bottom, ibotenic acid injections. All brains were examined $5 \mathrm{~d}$ after injections. Scale bar, $0.10 \mathrm{~mm}$. 


\section{REFERENCES}

Akana SF, Dallman MFW, Scribner KA, Strack AM, Walker C (1992a) Feedback and facilitation in the adrenocortical system: unmasking facilitation by partial inhibition of the glucocorticoid response to prior stress. Endocrinology 131:57-68.

Akana SF, Scribner KA, Bradbury MJ, Strack AM, Walker C-D, Dallman MF (1992b) Feedback sensitivity of the rat hypothalamo-pituitaryadrenal axis and its capacity to adjust to exogenous corticosterone. Endocrinology 131:585-594.

Akana SF, Strack AM, Hanson ES, Dallman MF (1994) Regulation of activity in the hypothalamo-pituitary-adrenal axis is integral to a larger hypothalamic system that determines caloric flow. Endocrinology 135: $1125-1134$.

Avrith D, Mogenson GJ (1978) Reversible hyperphagia and obesity following intracerebral microinjections of colchicine into the ventromedial hypothalamus of the rat. Brain Res 153:99-107.

Avrith D, Haas HL, Mogenson GJ (1979) Behavioral and electrophysiological changes following microinjections of colchicine into the substantia nigra. Neuroscience 4:227-234.

Bellinger LL, Bernardis LL, Mendel VE (1976) Effect of ventromedial and dorsomedial hypothalamic lesions on circadian corticosterone rhythms. Neuroendocrinology 22:216-225.

Beltt BM, Keesey RE (1975) Hypothalamic map of stimulation current thresholds for inhibition of feeding in rats. Am J Physiol 229:1124-1133.

Borg WP, During MJ, Sherwin RS, Borg MA, Brines ML, Shulman GI (1994) Ventromedial hypothalamic lesions in rats suppress counterregulatory responses to hypoglycemia. J Clin Invest 93:1677-1682.

Bradbury MJ, Cascio CS, Scribner KA, Dallman MF (1991) Stressinduced adrenocorticotropin secretion: diurnal responses and decreases during stress in the evening are not dependent on corticosterone. Endocrinology 128:680-688.

Bray GA, York DA (1979) Hypothalamic and genetic obesity in experimental animals: an autonomic and endocrine hypothesis. Physiol Rev 59:719-809.

Bray GA, Fisler J, York DA (1990) Neuroendocrine control of the development of obesity: understanding gained from studies of experimental animal models. Front Neuroendocrinol 11:128-181.

Canteras NS, Simerly RB, Swanson LW (1994) Organization of projections from the ventromedial nucleus of the hypothalamus: a Phaseolus vulgaris-leucoagglutinin study in the rat. J Comp Neurol 348:41-79.

Clark JT, Kalra PS, Crowley WR, Kalra SP (1984) Neuropeptide Y and human pancreatic polypeptide stimulate feeding behavior in rats. Endocrinology 115:427-429.

Dallman MF (1984) Viewing the ventromedial hypothalamus from the adrenal gland. Am J Physiol 246:R1-R11.

Dallman MF, Akana SF, Cascio CS, Darlington DN, Jacobson L, Levin N (1987) Regulation of ACTH secretion: variations on a theme of B. Recent Prog Horm Res 43:113-173.

Dallman MF, Akana SF, Strack AM, Hanson ES, Sebastian RJ (1995) The neural network that regulates energy balance is responsive to glucocorticoids and insulin and also regulates HPA axis responsivity at a site proximal to CRF neurons. Ann NY Acad Sci 771:730-742.

Egawa M, Inoue S, Sato S, Takamura Y, Murakami N, Takahashi K (1991) Restoration of circadian corticosterone rhythm in ventromedial hypothalamic lesioned rats. Neuroendocrinology 53:543-548.

Grossman SP, Dacey D, Halaris AE, Collier T, Routtenberg A (1978) Aphagia and adipsia after preferential destruction of nerve cell bodies in hypothalamus. Science 202:537-539.

Halaas JL, Gajiwala KS, Maffei M, Cohen SL, Chait BT, Rabinowitz D, Lallone RL, Burley SK, Friedman JM (1995) Weight-reducing effects of the plasma protein encoded by the obese gene. Science 269:543-546.

Hanson ES, Bradbury MJ, Akana SF, Scribner KS, Strack AM, Dallman MF (1994) The diurnal rhythm in adrenocorticotropin responses to restraint in adrenalectomized rats is determined by caloric intake. Endocrinology 134:2214-2220.

Honma S, Honma K, Nagasaka T, Hiroshige T (1987) The ventromedial hypothalamic nucleus is not essential for the prefeeding corticosterone peak in rats under restricted daily feeding. Physiol Behav 39:211-215.

Inouye SI (1982) Ventromedial hypothalamic lesions eliminate anticipatory activities of restricted daily feeding schedules in the rat. Brain Res 250:183-187.

Karteszi M, Dallman MF, Makara GB, Stark E (1982) Regulation of the adrenocortical response to insulin-induced hypoglycemia. Endocrinology 111:535-541.
Keller-Wood ME, Dallman MF (1984) Corticosteroid inhibition of ACTH secretion. Endocrine Rev 5:1-24.

Koizumi K, Nishino H (1976) Circadian and other rhythmic activity of neurones in the ventromedial nuclei and lateral hypothalamic area. J Physiol (Lond) 263:331-356.

Krieger DT (1980) Ventromedial hypothalamic lesions abolish foodshifted circadian adrenal and temperature rhythmicity. Endocrinology 106:649-654.

Li B, Spector AC, Rowland NE (1994) Reversal of dexfenfluramineinduced anorexia and c-Fos/c-Jun expression by lesion in the lateral parabrachial nucleus. Brain Res 640:255-267.

Mercer JG, Hoggard N, Williams LM, Lawrence CB, Hannah LT, Morgan PJ, Trayhurn P (1996) Coexpression of leptin receptor and preproneuropeptide $\mathrm{Y}$ mRNA in arcuate nucleus of mouse hypothalamus. J Neuroendocrinol 8:733-735.

Olney JW (1971) Glutamate-induced neuronal necrosis in the infant mouse hypothalamus. J Neuropathol Exp Neurol 30:75-90.

Olney JW, Ho OL, Rhee V (1971) Cytotoxic effects of acidic and sulphur containing amino acids on the infant mouse central nervous system. Exp Brain Res 14:61-76.

Ono T, Nishino H, Fukuda M, Sasaki K, Ken-Ichiro M, Oomura Y (1982) Glucoresponsive neurons in rat ventromedial hypothalamic tissue slices in vitro. Brain Res 232:494-499.

Oomura Y, Kita H (1981) Insulin acting as a modulator of feeding through the hypothalamus. Diabetologia 20:290-298.

Paulson JC, McClure WO (1974) Microtubules and axoplasmic transport. Brain Res 73:333-337.

Paxinos G, Watson C (1986) The rat brain in stereotaxic coordinates, Ed 2. Sydney: Academic.

Raff MC, Fields KL, Hakomori S, Mirsky R, Pruss RM, Winter J (1979) Cell-type-specific markers for distinguishing and studying neurons and the major classes of glial cells in culture. Brain Res 174:283-308.

Ritter S, Calingasan NY (1993) Lateral parabrachial subnucleus lesions abolish feeding induced by mercaptoacetate but not by 2-deoxy-Dglucose. Am J Physiol 265:R1168-R1178.

Sakaguchi T, Bray GA, Eddlestone G (1988) Sympathetic activity following paraventricular ventromedial hypothalamic lesions in rats. Brain Res Bull 20:461-465.

Schwartz MW, Sipols AJ, Marks JL, Sanacora G, White JD, Scheurink A, Kahn SE, Baskin DG, Woods SC, Figlewicz DP, Porte Daniel (1992) Inhibition of hypothalamic neuropeptide $\mathrm{Y}$ gene expression by insulin. Endocrinology 130:3608-3616.

Shimizu N, Oomura Y, Plata-Salaman CR, Morimoto M (1987) Hyperphagia and obesity in rats with bilateral ibotenic acid-induced lesions of the ventromedial hypothalamic nucleus. Brain Res 416:153-156.

Suemaru S, Darlington DN, Akana SF, Cascio CS, Dallman MF (1995) Ventromedial hypothalamic lesions inhibit corticosteroid feedback regulation of basal ACTH during the trough of the circadian rhythm. Neuroendocrinology 61:453-463.

Swanson LW (1992) Brian maps: structure of the rat brain. Amsterdam: Elsevier.

Takamiya Y, Kohsaka S, Toya S, Otani MO, Tsukada Y (1988) Immunohistochemical studies on the proliferation of reactive astrocytes and the expression of cytoskeletal proteins following brain injury in rats. Dev Brain Res 38:201-210.

Ter Horst GJ, Luiten PGM (1986) The efferent projections of the dorsomedial hypothalamic nucleus in the rat. Brain Res Bull 307:231-248.

Tokunaga K, Fukushima M, Lupien JR, Bray GA, Kemnitz JW, Schemmel R (1989) Effects of food restriction and adrenalectomy in rats with VMH or PVH lesions. Physiol Behav 45:1131-1137.

Topp KS, Faddis BT, Vijayan VK (1989) Trauma-induced proliferation of astrocytes in the brains of young and aged rats. Glia 2:201-211.

Wilson L (1975) Action of drugs on microtubules. Life Sci 17:303-310.

Zaia TBW, Oller Do Nascimento CMP, Timo-Iaria C, Dolnikoff MS (1987) Time course of insulin, corticosterone and metabolic changes caused by lesion of the ventromedial hypothalamus in the rat. Physiol Behav 39:707-714.

Zhang Y, Proenca R, Maffei M, Barone M, Leopold L, Friedman JM (1994) Positional cloning of the mouse obese gene and its human homologue. Nature 372:425-432.

Zolovick AJ, Arrith D, Jalowiec JE (1977) Reversible colchicine-induced disruption of amygdaloid function on sodium appetite. Brain Res Bull 5:35-39. 